\title{
Measuring the Cognitive Impact of Laughter on Elderly People with Mild Cognitive Impairment in Japan
}

\author{
Miwa Yamamoto ${ }^{1}$, Shizue Mizuno ${ }^{1}$, Masako Aota $^{2}$, Yoko Murakami $^{3}$ \\ ${ }^{1}$ Department of Nursing, Kyoto Koka Women's University, Kyoto, Japan; ${ }^{2}$ Meiji University of Integrative Medicine, Kyoto, Japan; \\ ${ }^{3}$ Aino University, Osaka, Japan. \\ Email: tokiwa27@hotmail.com
}

Received July $8^{\text {th }}, 2012$; revised August $16^{\text {th }}, 2012$; accepted September $10^{\text {th }}, 2012$

\begin{abstract}
Objective: To evaluate the effect of laughter on cognition in elderly with mild cognitive impairment (MCI) through an appropriately designed intervention. Methods: The intervention involved watching a Japanese comedy routine (Manzai) for approximately twenty minutes, once a week for ten weeks. Participants were asked to paint, as a simple exercise, in addition to watching the show. Twenty-seven patients with MCI from the convalescent ward of a general hospital in the Kansai region of Japan. We measured cognition by evaluating five cognitive function domains before (baseline) and after the intervention. We used the Wilcoxon signed rank test, a distribution-free method, to compare baseline and post-intervention data. Ethical Consideration: Participants were given a document explaining the study. Only those who officially agreed to participate were enrolled. Results: Mean age of patients was $85.0 \pm 2.8$ years; average education was $8.6 \pm 2.8$ years. Three cognitive function domains had significantly different average scores after the intervention: 1) Exercise: $44.4 \pm 8.9$ points at baseline, $36.3 \pm 10.2$ post-intervention $(p=0.014) ; 2)$ Word memory: $40.6 \pm 7.2$ at baseline, $43.1 \pm 8.8$ post-intervention ( $\mathrm{p}=0.002)$; and 3) Animal name recollection: $35.3 \pm 8.4$ at baseline, $38.1 \pm 9.0$ post-intervention $(p=0.003)$. Discussion: The intervention led to significantly higher cognitive scores in exercise, word memory, and animal name recollection domains, suggesting that interventions focused on laughter and simple exercise may improve cognition in elderly patients with MCI.
\end{abstract}

Keywords: Cognitive Impact; Laugh; Elderly People; Mild Cognitive Impairment

\section{Introduction}

A lot of data from previous study shows effects of cognitive function from diversional therapy in the world [1-4]. S. L. Wheeler, and K. Houston examined the power of milieu therapy in the general medical setting in USA [1]. B. P. Leifer says early intervention is critical because a delay in treatment is associated with nonreversible symptom progression. Realistic treatment expectations include reduction in symptom severity and slowed decline in cognition, function, and behavior [3]. G. Sanchez-Benavides, et al. illuminated to test the discriminant and concurrent validity of the Spanish version of the Bayer Activities of Daily Living scale (B-ADL) in mild cognitive impairment (MCI) and mild Alzheimer disease (AD) in Spain [4]. At the same time, previous study shows effects of cognitive function from diversional therapy in Japan [5-8]. These articles imply that it is important to consider about cultural and individual contents for elderly people in each countries. Therefore, we would think Japanese cultural diversional therapy for elderly people with dementia in Japan. Moreover, "MANZAI" performance is traditional Japanese comic chat form comedian in Japan. "MANZAI" is one of a traditional style of stand-up comedy in Japanese culturral entertainments, which usually involves two performers (manzai-shi). "MANZAI" has often been associated with the Osaka region, and manzai comedians often speak in the Kansai dialect during their acts. Almost Kansai people like "MANZAI" performance. A great deal of effort has been made on clarify effect of "MANZAI". What seems to be lacking, however, is to clarify effect of laughing of "MANZAI" for cognitive function of elderly people.

\section{Objectives}

To evaluate the effect of laughter on cognition in elderly with mild cognitive impairment (MCI) through an appropriately designed intervention in Japan.

\section{Methods}

The intervention involved watching a Japanese comedy routine (Manzai) for approximately twenty minutes, once a week for ten weeks. Participants were asked to paint, as 
a simple exercise, in addition to watching the show. Twenty-seven patients with MCI from the convalescent ward of a general hospital in the Kansai region of Japan. We measured cognition by evaluating five cognitive function domains before (baseline) and after the intervention [9]. We used the Wilcoxon signed rank test, a distribution-free method, to compare baseline and postintervention data. Ethical consideration: Participants were given a document explaining the study. Only those who officially agreed to participate were enrolled.

\section{Results}

Mean age of patients was $85.0 \pm 2.8$ years; average education was $8.6 \pm 2.8$ years (Table 1). Three cognitive function domains had significantly different average scores after the intervention: 1) Exercise: $44.4 \pm 8.9$ points at baseline, $36.3 \pm 10.2$ post-intervention $(\mathrm{p}=0.014) ; 2)$ Word memory: $40.6 \pm 7.2$ at baseline, $43.1 \pm 8.8$ postintervention ( $\mathrm{p}=0.002)$; and 3$)$ Animal name recollection: $35.3 \pm 8.4$ at baseline, $38.1 \pm 9.0$ post-intervention $(\mathrm{p}=$ $0.003)$.

\section{Discussion}

Mean age of patients was $85.0 \pm 2.8$ years; average education was $8.6 \pm 2.8$ years.

Three cognitive function domains had significantly different average scores after the intervention: 1) exercise: $44.4 \pm 8.9$ points at baseline, $36.3 \pm 10.2$ post-intervention ( $p=0.014) ; 2$ ) word memory: $40.6 \pm 7.2$ at baseline, $43.1 \pm 8.8$ post-intervention $(\mathrm{p}=0.002)$; and 3$)$ animal name recollection: $35.3 \pm 8.4$ at baseline, $38.1 \pm 9.0$ post-intervention $(\mathrm{p}=0.003)$.

The intervention led to significantly higher cognitive scores in exercise, word memory, and animal name recollection domains, suggesting that interventions focused

Table 1. Mean age and average education of patients.

\begin{tabular}{cc}
\hline & Years \\
\hline Mean age of patients & $85.0 \pm 2.8$ \\
Average education & $8.6 \pm 2.8$ \\
\hline
\end{tabular}

on laughter and simple exercise may improve cognition in elderly patients with MCI.

\section{Acknowledgements}

The author thanks all participants of this study.

\section{REFERENCES}

[1] S. L. Wheeler and K. Houston, "The Role of Diversional Activities in the General Medical Hospital Setting," Holist Nursing Practice, Vol. 19, No. 2, 2005, pp. 87-89.

[2] A. Sudhindra, "Huntington's Chorea: Implications for Nursing in India," Nursing Journal of India, Vol. 80, No. 4, 1989, pp. 97-99.

[3] B. P. Leifer, "Alzheimer's Disease: Seeing the Signs Early," Journal of American Academy of Nurse Practitioners, Vol. 21, No. 11, 2009, pp. 588-595. doi:10.1111/j.1745-7599.2009.00436.x

[4] G. Sanchez-Benavides, et al., "Spanish Version of the Bayer Activities of Daily Living Scale in Mild Cognitive Impairment and Mild Alzheimer Disease: Discriminant and Concurrent Validity," Dementia and Geriatric Cognitive Disorders, Vol. 27, No. 6, 2009, pp. 572-578. doi:10.1159/000228259

[5] W. Zhou, S. Fukumoto and H. Yokogoshi, "Components of Lemon Essential Oil Attenuate Dementia Induced by Scopolamine," Nutritional Neuroscience, Vol. 12, No. 2, 2009, pp. 57-64. doi:10.1179/147683009X388832

[6] A. Yoritaka, et al., "Parkinson's Disease with and without REM Sleep Behaviour Disorder: Are There Any Clinical Differences?" European Neurology, Vol. 61, No. 3, 2009, pp. 164-170. doi:10.1159/000189269

[7] T. Yonezawa, et al., "Influence of the Timing of Surgery on Mortality and Activity of Hip Fracture in Elderly Patients," Journal of Orthopaedic Science, Vol. 14, No. 5, 2009, pp. 566-573. doi:10.1007/s00776-009-1380-5

[8] K. Yasuda, et al., "Effectiveness of Personalised Reminiscence Photo Videos for Individuals with Dementia," Neuropsychological Rehabilitation, Vol. 19, No. 4, 2009, pp. 603-619. doi:10.1080/09602010802586216

[9] Y. Naomi and A. Takashi, "Development of Five Cognitive Function Tests for Group of Older People's Cogni tion," Japanese Psychogeriatric Society, Vol. 17, 2006, p. 174. 